\title{
T证 A REMOTE HEALTH MONITORING SYSTEM FOR RURAL AREAS
}

\author{
Naveen Kuma Munjal, Shiv Ratan Singh \\ E-Mail Id: naveenmunjal.dce@gmail.com, ssratan2014@gmail.com \\ Guru Nanak Dev Institute of Technology, Delhi
}

\begin{abstract}
The diagnosis of a patient primarily involves measurement of vital parameters such as temperature, blood pressure, heart rate and ECG. The focus of this paper is to create a remote medical diagnosis system for remote and rural areas where there is dearth of medical clinics and doctors. The paper presents an IOT architecture customized for two applications: physical sensors for rooms which records data of the user and relays it to the servers via the Internet where it is processed and analysed. Feedback actions based on the analysed data can be sent back to the user. A prototype of the proposed architecture has been built to demonstrate its performance advantages.
\end{abstract}

Index Terms: Blood pressure sensor, ECG sensor, IOT, PIC microcontroller, Pulse rate sensor, Remote healthcare, Temperature sensor

\section{INTRODUCTION}

Rural healthcare is one of the biggest challenges that India is facing today. With more than seventy per cent of population living in rural areas and low level of health facilities, mortality rates due to diseases are on a high. Considering the picture of grim facts there is a dire need of new practices and procedures to ensure that quality and timely healthcare reaches the underprivileged corners of our country. IOT is an innovative tool that could play a critical role in meeting these requirements.

An IOT healthcare system ties all the accessible resources as a set of links to achieve healthcare activities like diagnosis, monitoring and remote operations over the Internet. IOT forms a network of devices which can communicate with each other in real time. Such a network can be exploited to securely access a patient's health information by means of a selection of sensors, apply complex algorithms to examine the data and then transmit it via wireless connection to the medical experts who can suggest suitable healthcare action.

The physical sensors selected are such that they provide holistic information of a patient's health. A combination of four sensors is used to acquire data about body temperature, heart rate, blood pressure and ECG information. Information about these conditions provides the first symptoms of any ailments in the human body. These sensors are reliable and easy to use. Monitoring patient's body using these sensors can avert dangerous situations by providing continuous monitoring in the absence of medical facilities and doctors at remote locations. The sensors are interfaced with microcontroller which sends the data acquired from patients to the designated servers where the medical experts can recommend further actions required. This system utilizing sensors and a network of devices is highly suitable to the present situation of our country. It would provide an economical, reliable and technically advanced way of treatment to the remotest population. Figure 1 describes the various components of the system.

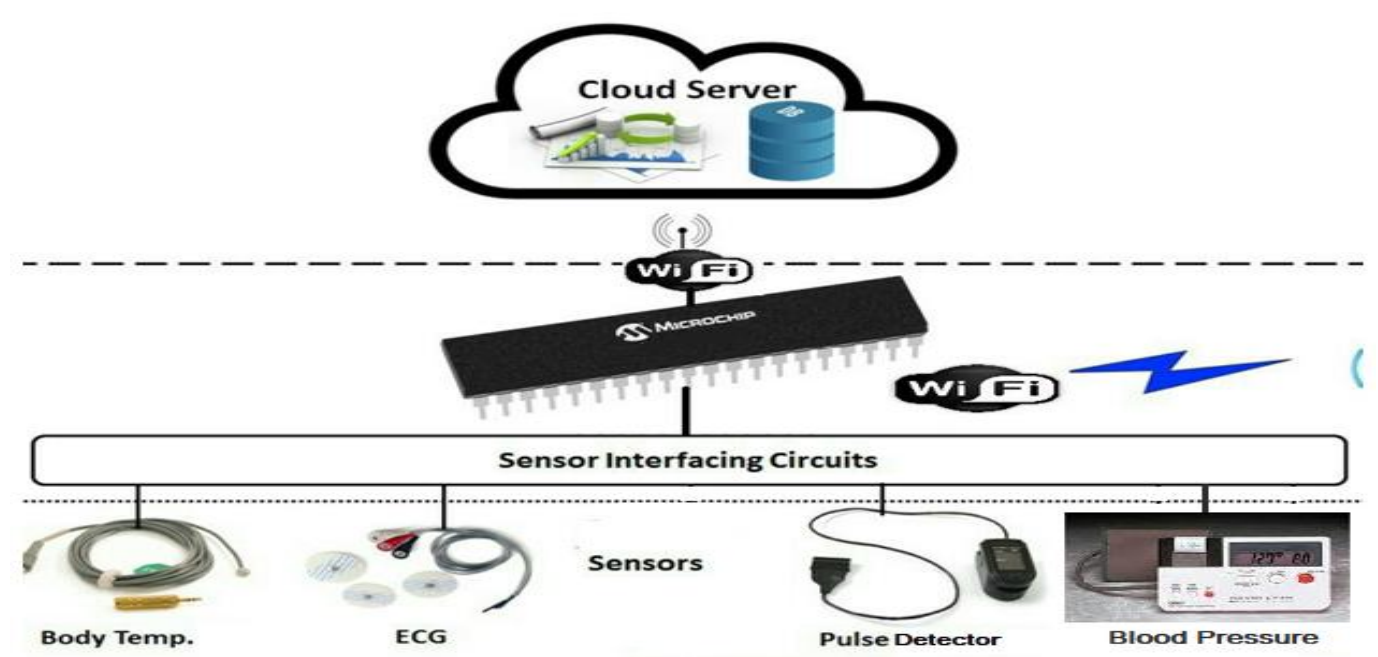

Fig. 1.1 Block Diagram Showing Different Components of The Proposed System

\section{LITERATURE SURVEY}

The importance of wireless sensor networks in procuring biological and behavioural data from subjects for diagnosis, monitoring, or disease management was recognised by Afsaneh et al in [1]. They focused on DOI Number: https://doi.org/10.30780/IJTRS.V05.I06.001

pg. 1

WWW.ijtrs.com

wWw.ijtrs.org 


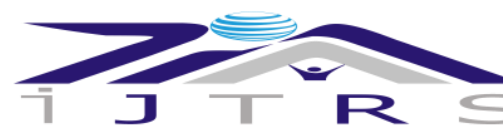

\section{International Journal of Technical Research \& Science}

providing at home healthcare for the elderly using communication devices such as mobile phones and Internet to keep the care givers informed. The authors in [2], [3] and [4] have developed a health monitoring system based on Short Message Service (SMS). It is a fairly remarkable system but unable to intimation real time for the medical help. Sudarshan et al [5] developed a system to detect any eventual fall of senior citizens at their home using a principle of hybrid fall detection but it also suffers with a drawback of non-provision of conveying data to the medicare representatives immediately. Kumar et al [6] presented a system to acquire medical parameters based on android. But it is complex as it uses micro electro mechanical devices and is not suitable for economic and widespread use. In [7], [8] and [9] the authors have proposed various wearable devices employing sensors for monitoring of patient but the hardware and computational requirements for the wearable medicare devices can be a restraining feature for continuous connectivity and data handling. Ramesh et al [10] used temperature sensors to collect information about different areas in the business and make research using that information. This type of framework can provide valuable data pertaining to agribusiness, human services, stockpiling ranges and so forth. In [11], [12], [13] and [14] the authors have designed a wireless health monitor system based on Arduino that combines data and transmits it for storage and analysis. In [15], [16] and [17] the authors have proposed a system based on biosensors that would continuously monitor the patient an aggregate data and send it to backend. Although copious research has been done in this field recently but still there is a need of anallinclusive system which can deliver real time diagnosis at a remote location for several categories of disorders by monitoring of different types of conditions.

The aim of our paper is to provide an all-included system for holistic monitoring and real time diagnosis of patients at remote locations or rural areas with low medical facilities. The proposed system utilizes four sensors to monitor a patient's condition. These include LM35 temperature sensor, SEN-11574 pulse rate sensor, AD8232 ECG sensor and UA-767 PC blood pressure monitor. The temperature, pulse rate, ECG and blood pressure are the most important indicators of human health. They are the primary signs which are checked in case of any disorders. The data from these sensors is sent over the Internet to the designated servers where the assigned doctors can take requisite actions. The servers also provide a means to store history of the patients and generate comparative reports for diagnosis and monitoring purposes. This system works to reduce the stress on rural population who wander to distant places in search of doctors and medical facilities. It also reduces stress on the government from the need to send expert doctors in every village and underdeveloped or remote areas by providing diagnosis by experts over the Internet.

\section{PROPOSED SYSTEM}

The proposed system is designed to allow the people at remote locations such as rural areas with limited or no medical facilities to test themselves using the sensor network provided and get proper treatment over the Internet. The system is composed of five modules: the physical sensors that collects the user's information and provides the desired feedback, a sensor interfacing circuit, a low power microcontroller that manages the data collection and forwarding processes, a wireless trans receiver that connects the system to the internet and a server in which the data storage and processing take place.

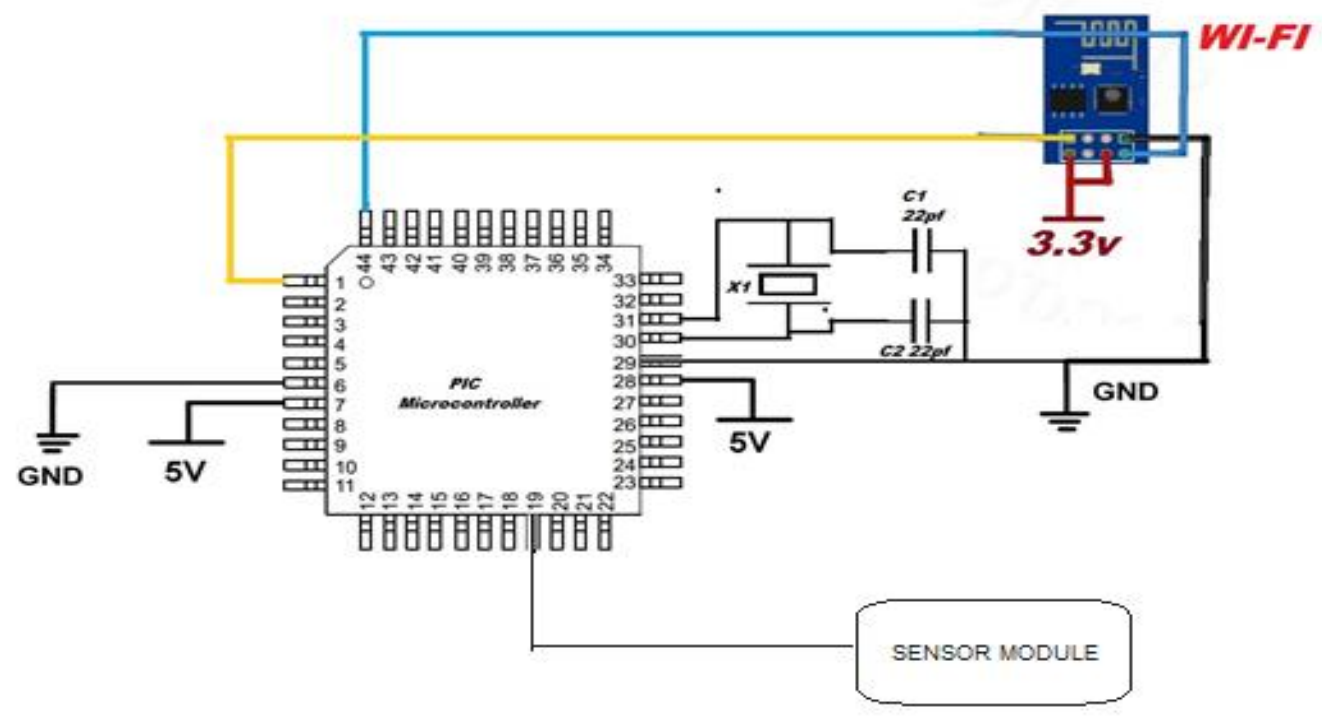

Fig. 3.1 Circuit Diagram Describing the Architecture of the System

The sensors play a major role in this health care facility. Temperature, pulse rate, ECG and blood pressure are the primary elements which are monitored to check if there is any distress situation for the body. In this paper four sensors are employed to monitor the aforementioned conditions. The temperature sensor (LM-35) is used to measure the body temperature of a patient. SEN-11574 pulse rate sensor is used to detect live heart rate. 


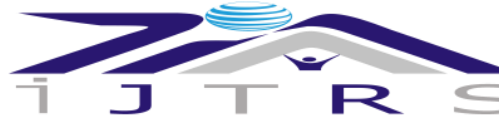

\section{International Journal of Technical Research \& Science}

AD8232 ECG sensor module is used to measure the rhythm of heart and blood flow through it. Lastly, UA-767 PC blood pressure monitor is used to measure the level of blood pressure. These sensors are together interfaced with PIC microcontroller. Then, a server and web page part is introduced with respect to IOT which acts as a link between the patient and doctor. Fig. 3.1 shows the detailed circuit diagram of the system.

\subsection{Sensors}

LM35: Assessment of body temperature is vital for decisions in nursing care, medical diagnosis, treatment and the need of laboratory tests. The LM35 is a precision integrated circuit temperature instrument whose output voltage varies linearly with Centigrade temperature.

It has low output impedance and linear output which assists the interfacing of LM35 to read out or control circuits especially very easy. It is a low power consumption device drawing only $60 \mu \mathrm{A}$ from the supply. It is rated to operate over a temperature range of $-55^{\circ} \mathrm{C}$ to $150^{\circ} \mathrm{C}$. The normal body temperature is $37^{\circ} \mathrm{C}$ which can go up to $42.4^{\circ} \mathrm{Cin}$ case of intolerable fever. Thus the sensor is well suited to human body's temperature range. The precision specifications of the LM35are given with respect to a simple linear transfer function: $V_{\text {OUT }}=10 \mathrm{mV} /{ }^{\circ} \mathrm{C} \times T$ where $V_{\text {OUT }}$ is the LM35outputvoltage and T is the temperature in ${ }^{\circ} \mathrm{C}$.

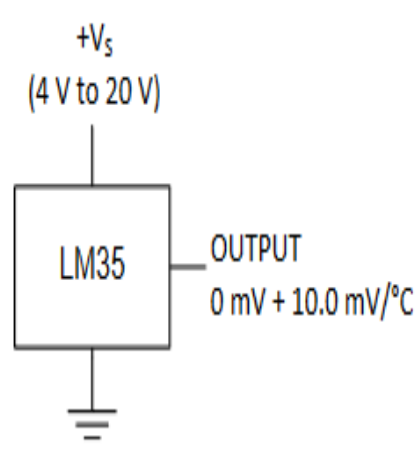

Fig. 3.2 Block Diagram (LM35)

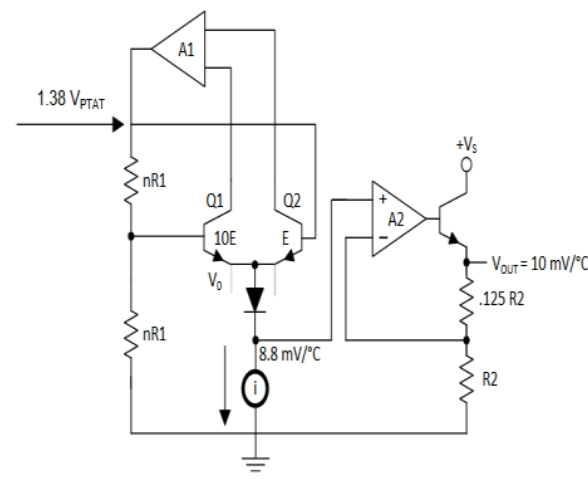

Fig. 3.3 Circuit Diagram (LM35)

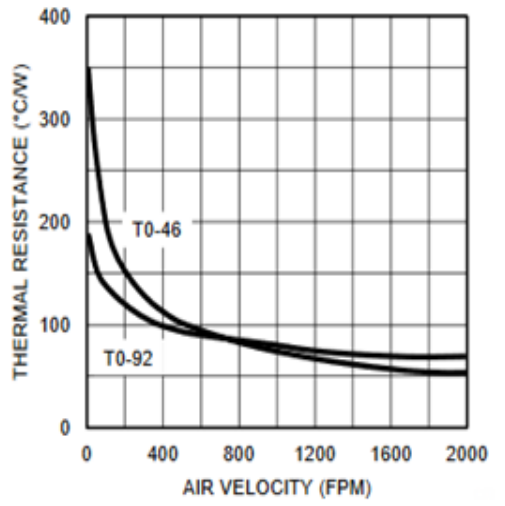

Fig. 3.4 Thermal Resistance Junction To Air Of LM35

SEN-11574: Pulse Sensor is a well-made plug-and-play heart-rate sensor that can be interfaced with PIC 18F4620. The sensor clasps onto a fingertip or earlobe on one side and plugs into PIC 18F4620on the other side with some jumper cables. Additionally, it includes an open-source nursing app that graphs your pulse in real time.

AD8232: Electrocardiography is a technique used to analyse the conduction system of the heart, which delivers us the statistics about the heart's electrical activity. The recording of this conduction system is substantially denoted as an ECG. This non-invasive and quick examination makes it possible to gauge the electrical activity of the heart and to discover potential cardiac issues. The AD8232 is an integrated circuit module for measurement of ECG and additional biopotential applications. It extracts, amplifies, and filters weak biopotential signals in the presence of noisy settings, such as those formed by movements or remote electrode location. It allows for an embedded microcontroller or a low power analog-to-digital converter (ADC) to acquire the output signal conveniently.

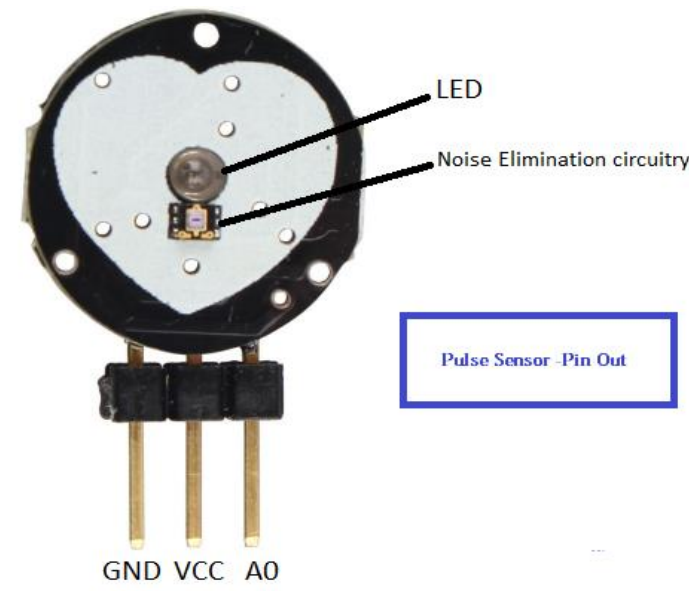

Fig. 3.5 Pulse Sensor (11574)

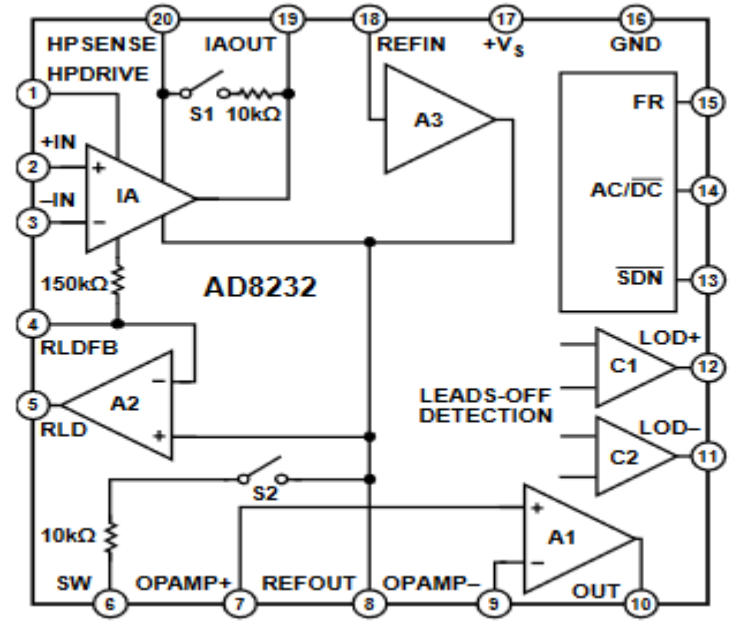

Fig. 3.6 Internal Structure of AD8232 


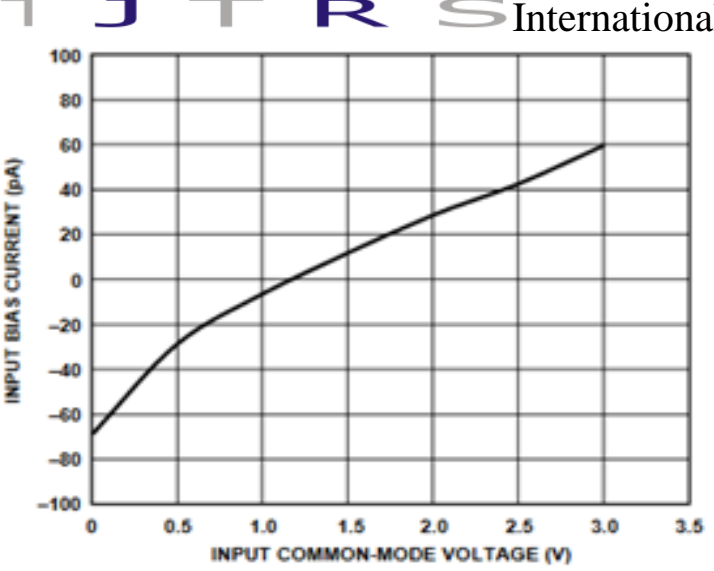

Fig. 3.7 Operational Amplifier Bias Current Vs. Input Common Mode

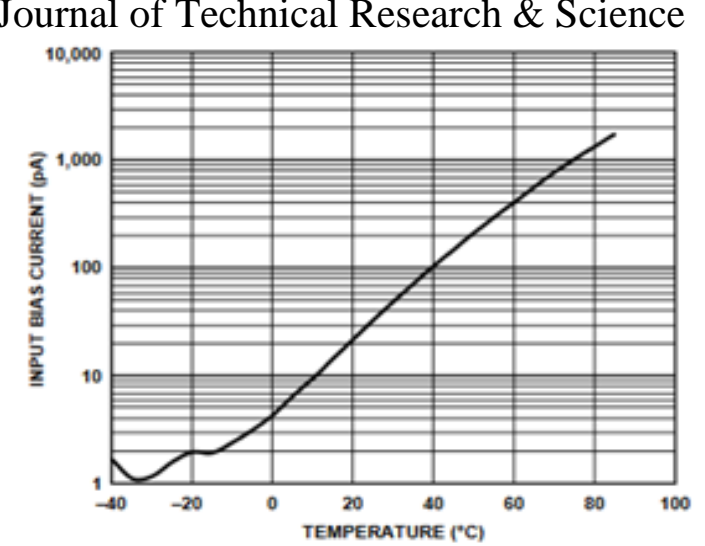

Fig. 3.8 Operational Amplifier Bias Current Vs. Temperature

UA767: Hypertension is abnormally high blood pressure. It can lead to several health problems including stroke and heart attack if left unattended. UA767 blood pressure monitor is easy to use, precise and digitally displays full measurement output. The technology is centred on the "oscillometric method" - a non-invasive blood pressure determination. The term "oscillation" denotes any degree of vibrations produced by the arterial pulse. The sensor monitors the pulsatile pressure produced by the arterial wall as it expands and contracts against the cuff with each heartbeat.

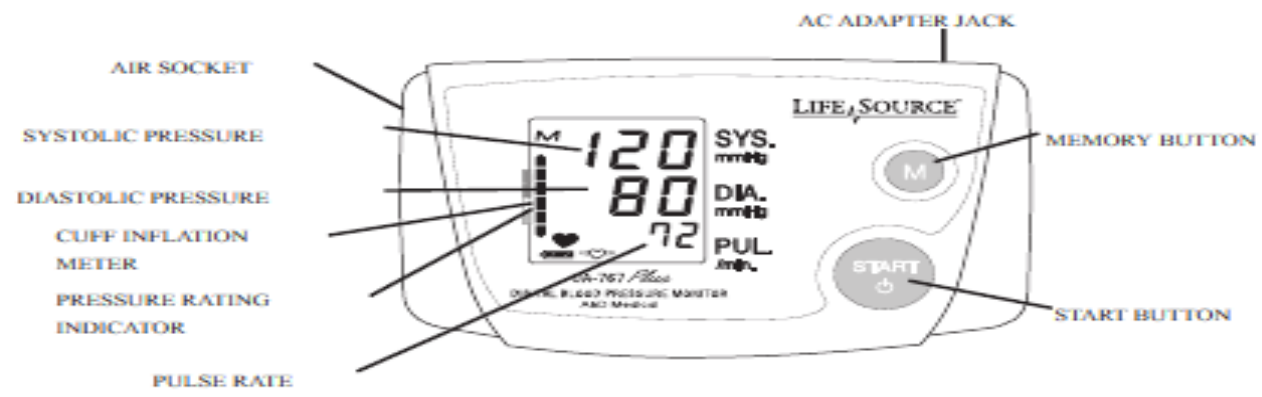

Fig. 3.9 UA767 Blood Pressure Detector

PIC Microcontroller PIC18F4620: In the proposed system, PIC microcontroller based on PIC18F4620 datasheet is used. It is a 40 pin IC operating on frequency of $40 \mathrm{MHz}$ with 13 input/output channels, 20 interrupt lines, 75 instruction set that is extendible up to 83 instructions and a program memory of 65536 bytes.

\begin{tabular}{|c|c|c|}
\hline 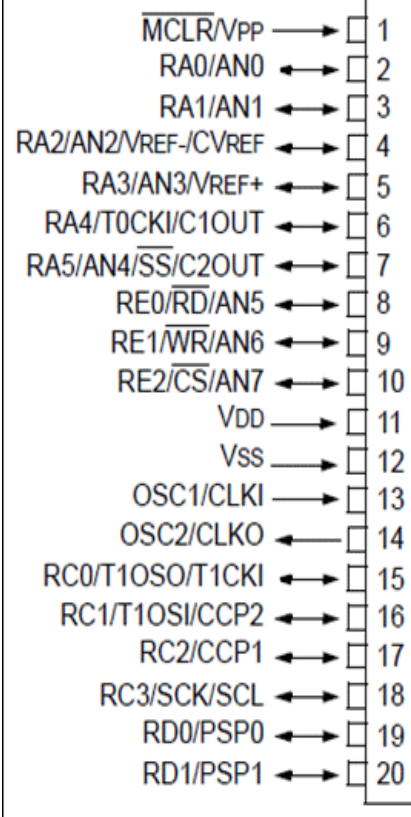 & $\begin{array}{l}40 \\
39 \\
38 \\
37 \\
36 \\
35 \\
34 \\
33 \\
32 \\
31 \\
30 \\
29 \\
28 \\
27 \\
26 \\
25 \\
24 \\
23 \\
22 \\
21 \\
\end{array}$ & 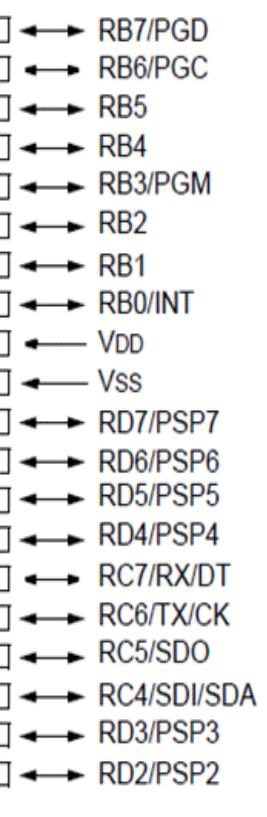 \\
\hline
\end{tabular}

Fig. 3.10 Pin Diagram of PIC18F4620 


\section{RESULT}

The proposed system has been tested under laboratory conditions for measuring the temperature, blood pressure, pulse rate and ECG of various subjects. The results are displayed on the screen so that the patient can see them while they are transmitted to the doctors. The results are transmitted to the doctors via Internet and the corresponding medicines are prescribed to the patient in a similar fashion. The results show that the proposed system is capable of measurement of vital parameters with high accuracy thereby reducing the load on medical staff requirements in remote areas. However such a system requires the patient to acquire the knowledge of use of sensors which can cause discomfort to the patients.

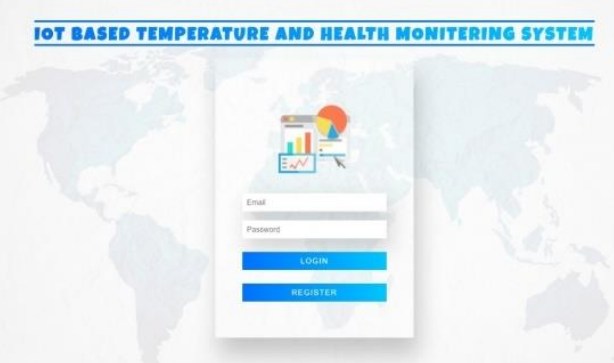

Fig. 4.2 Server Side user Interface

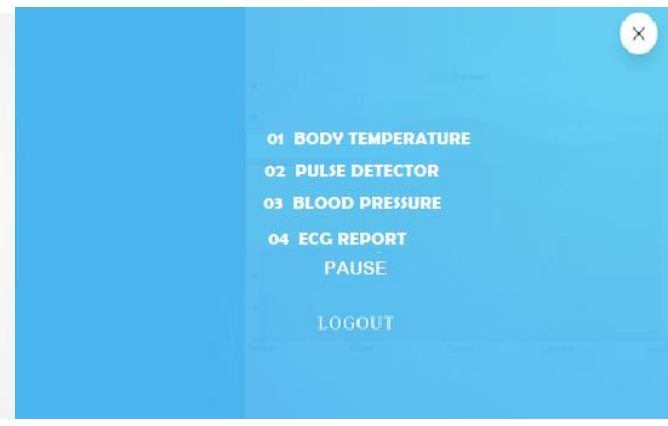

Fig. 4.2 Patient Side User Interface

Figure 12, 13 shows the user interface of the server side and patient side. They are designed to be simple and user friendly to cater to the needs of users with limited computer skills. Figure 14 shows the display of the body temperature of the user. LM35 sensor is responsible for detecting the body temperature of the user which is recorded and transmitted via the Internet. The recorded temperature is displayed accompanied with normal temperature range of different age groups so that the users can also check for themselves.

\section{TEMPERATURE}

\section{NORMAL BODY TEMPERATURE RANGES}

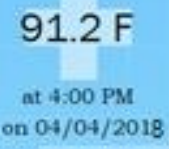

\begin{tabular}{|c|c|c|c|c|}
\hline${ }^{\circ} \mathrm{F}$ & 0.2 years & $3 \cdot 10$ years & 11.65 years & $>65$ years \\
\hline Ord & - & $95.9 \quad 995$ & $976 \quad 996$ & $98.4 \quad 985$ \\
\hline Rectal & $979 \quad 1004$ & $979 \quad 1004$ & $986 \quad 1006$ & 971.992 \\
\hline Axllary & $945 \quad 98.1$ & $966 \quad 990$ & $953 \quad 984$ & $950 \quad 97.4$ \\
\hline Ear & $975 \quad 1004$ & $970 \quad 1000$ & $966 \quad 997$ & $96.4 \quad 995$ \\
\hline Core & $97.5 \quad 1000$ & $97.5 \quad 100.0$ & $\$ 82 \quad 1002$ & $\$ 66 \quad 988$ \\
\hline
\end{tabular}

Fig. 4.3 Display of Body Temperature of the User

SEN11574 pulse detection module detects the pulse rate and displays it on screen. The recorded pulse rate can be compared with range of normal pulse rate values which are displayed on screen. Figure 15 shows the result for pulse detection.

\begin{tabular}{|c|c|c|c|c|c|c|c|}
\hline \multirow[b]{2}{*}{ PULSE RATE } & \multicolumn{2}{|c|}{ Age $18-25$} & $26-35$ & $36-45$ & $46-55$ & $56-65$ & $65+$ \\
\hline & Athlete & $49-65$ & $49-64$ & $50-56$ & $50-67$ & $51-56$ & $50-55$ \\
\hline $110 \mathrm{BPM}$ & Excellent & $56-61$ & $55-61$ & $57-62$ & $58-63$ & $57-61$ & $56-61$ \\
\hline & Good & $62-65$ & $62-65$ & $63-66$ & 64.67 & $62-67$ & $62-65$ \\
\hline at 4:00 PM & Above Average & $66-69$ & $66-70$ & $67-70$ & $68-71$ & $68-71$ & $66-69$ \\
\hline on $04 / 04 / 2018$ & Average & $70-73$ & $71-74$ & $71-75$ & $72-76$ & $72-75$ & $70-73$ \\
\hline & Below Average & $74-81$ & $75-81$ & $76-82$ & $77-83$ & $76-81$ & $74-79$ \\
\hline & Poor & $82+$ & $82+$ & $83+$ & $84+$ & $82+$ & $80+$ \\
\hline
\end{tabular}

Fig. 4.4 Display of Pulse Rate of the User

Figure 16 shows the recorded systolic and diastolic blood pressure detected by UA767. The system displays the values and also shows a range of values for the user. 


\begin{tabular}{|c|c|c|c|c|}
\hline \multirow{3}{*}{$\begin{array}{l}\text { BLOOD PRESSURE } \\
\text { SYSTOLIC }: 132 \\
\text { DIASTOLIC }: 86\end{array}$} & Category & Systolic & & Diastolic \\
\hline & Optimál & $<120$ & and & $<80$ \\
\hline & Normal & $120-129$ & and/or & $80-84$ \\
\hline \multirow{5}{*}{$\begin{array}{c}\text { at 4:00 PM } \\
\text { on } 04 / 04 / 2018\end{array}$} & High normal & $130-139$ & and/or & $85-89$ \\
\hline & Grade I hypertension & $140-159$ & and/or & $90-99$ \\
\hline & Grade 2 hypertension & $160-179$ & and/or & $100-109$ \\
\hline & Grade 3 hypertension & $\geq 180$ & and/or & $\geq 110$ \\
\hline & Isolated systolic hypertension & $\geq 140$ & and & $<90$ \\
\hline
\end{tabular}

Fig. 4.5 Display of Blood Pressure of the User

AD8232 is used to record the electric activity of the user's heart to look for any potential cardiac risks. Figure 17 displays the recorded chart for electrocardiography using AD8232. This data is transmitted further to the server end where the medical practitioners can carry on subsequent diagnosis.

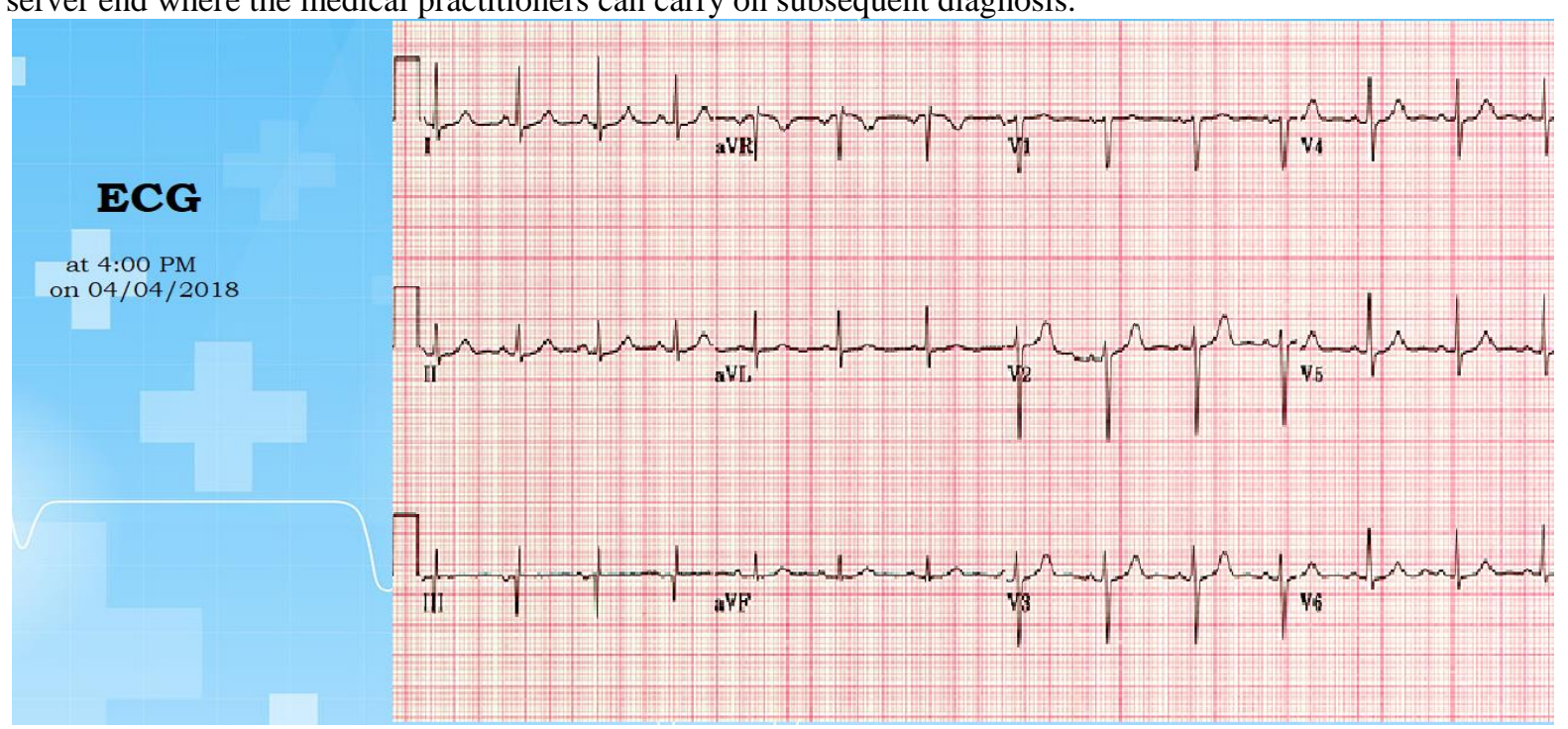

Fig. 4.6 Display of ECG of the User

\section{CONCLUSION}

Healthcare is the basic need and right of every individual but scarcity of quality infrastructure, lack of qualified medical functionaries, and inaccessibility to rudimentary medical facilities impedes its reach to $60 \%$ of population in India majority of which resides in rural areas. The current situation demands a critical paradigm shift to a technically advanced medical system for deeper penetration into remote areas. The aim of this paper is to develop a simple, reliable and accountable IOT based system designed to assess the vital health parameters of the user. The system utilises commercially available sensors for measurement of temperature, pulse rate, blood pressure and ECG. These values are then transmitted over the Internet to the server location where the available doctors can access this information and carry on with further diagnosis. The system is highly relevant in the current scenario in developing countries like India where there is a high focus on empowering rural areas with modern communication and digital technologies. The introduction of policies such as Ayushman Bharat, Bharat Net, Reproductive, Maternal, Newborn, Child and Adolescent Health (RMNCH+A), Rashtriya Bal Swasthya Karyakram (RBSK), Rashtriya Kishor Swasthya Karyakram (RKSK) emphasises the leverage being provided to healthcare facilities. The adaptation of technology to healthcare facilities is the way forward. Such systems as presented would not only reduce burden on the resources and but are far more economical than providing physical centres in remote areas.

\section{REFERENCES}

[1] Dr. Afsaneh Minaie, Dr. Ali Sanati-Mehrizy, “Application of Wireless Sensor Networks in Health Care System", 120th ASEE Annual Conference \& Exposition June 23-26, 2013

[2] Sanjay Verma, Namit Gupta,"Microcontroller-based Wireless Heart Rate Telemonitor for Home Care", IOSR Journal of Engineering (IOSRJEN) Vol. 2, Issue 7 (July 2012), pp. 25-31

DOI Number: https://doi.org/10.30780/IJTRS.V05.I06.001 
IR S International Journal of Technical Research \& Science

[3] Scanaill, Cliodhna Ni, Brian Ahearne, and Gerard M. Lyons. "Long-term telemonitoring of mobility trends of elderly people using SMS messaging." IEEE Transactions on Information Technology in Biomedicine 10.2 (2006): 412-413.

[4] Jain, Nitin P., Preeti N. Jain, and Trupti P. Agarkar. "An embedded, GSM based, multiparameter, realtime patient monitoring system and control-An implementation for ICU patients." 2012 World Congress on Information and Communication Technologies. IEEE, 2012.

[5] Sudarshan B G, Raveendra Hegde, Prasanna Kumar S C, Satyanarayana B S, "Design and Development of Fall detector using Fall Acceleration", International Journal of Research in Engineering and Technology.

[6] Kumar Kandukuri A. Amala Jency R, Anita, K.S. Pavithra, V Seema,"Android Based Women Safety Application with Blood Pressure, Heart Beat Monitoring and Location Tracking, Emergency Support System", IJSRD - International Journal for Scientific Research \& Development, Vol. 3, Issue 01, 2015

[7] Majumder S, Mondal T, Deen MJ. Wearable Sensors for Remote Health Monitoring. Sensors (Basel). 2017; 17(1):130. Published 2017 Jan 12. doi:10.3390/s17010130

[8] V. Ramesh, M. Sankaramahalingam, M. S. D. Bharathy and R. Aksha, "Remote temperature monitoring and control using IoT," 2017 International Conference on Computing Methodologies and Communication(ICCMC),Erode,2017,pp.1059-1063,doi:10.1109/ICCMC.2017.8282633

[9] Pandian, P. S., et al. "Smart Vest: Wearable multi-parameter remote physiological monitoring system." Medical engineering \& physics 30.4 (2008): 466-477.

[10] Gatzoulis, Loukianos, and Ilias Iakovidis. "Wearable and portable eHealth systems." IEEE Engineering in Medicine and Biology Magazine 26.5 (2007): 51-56.

[11] Alisinanoglu, Fatih. (2015). Wireless Blood Pressure Monitoring System. 10.13140/RG.2.1.2104.5609.

[12] Hassanalieragh, Moeen, et al. "Health monitoring and management using Internet-of-Things (IoT) sensing with cloud-based processing: Opportunities and challenges." 2015 IEEE International Conference on Services Computing. IEEE, 2015.

[13] Gope, Prosanta, and Tzonelih Hwang. "BSN-Care: A secure IoT-based modern healthcare system using body sensor network." IEEE Sensors Journal 16.5 (2016): 1368-1376.

[14] Khan, Sarfraz Fayaz. "Health care monitoring system in Internet of Things (IoT) by using RFID." 2017 6th International Conference on Industrial Technology and Management (ICITM). IEEE, 2017.

[15] Liang, Xiaohui, et al. "Enabling pervasive healthcare through continuous remote health monitoring." IEEE Wireless Communications 19.6 (2012): 10-18.

[16] Virone, Gilles, et al. "An advanced wireless sensor network for health monitoring." Transdisciplinary conference on distributed diagnosis and home healthcare (D2H2). 2006.

[17] Mohomed, Iqbal, et al. "Harmoni: Context-aware filtering of sensor data for continuous remote health monitoring." 2008 Sixth Annual IEEE International Conference on Pervasive Computing and Communications (PerCom). IEEE, 2008. 